\title{
e-Insurance ou Seguros Digitais: As Tecnologias de Informação e Comunicação utilizadas pelas principais empresas seguradoras do Brasil
}

\author{
Lucas Queiroz FERREIRA \\ Universidade Federal de Pernambuco (UFPE), Caruaru, PE, Brasil
}

Francisco Carlos Lopes da SILVA
Universidade Federal de Pernambuco (UFPE), Caruaru, PE, Brasil

Érica Souza SIQUEIRA

Escola de Administração de Empresas de São Paulo (EAESP/FGV), São Paulo, SP, Brasil

Received 16 dez. 18; Accepted 1 febr. 19

Evaluation System: Double Blind-Review

Editor: Jose Lindenberg Julião Xavier Filho, Dr. ISSN: 2594-8040

To cite this paper: Ferreira, L. Q., Silva. F. C. L., \& Siqueira, E. S. (2018). E-Insurance ou Seguros Digitais: As Tecnologias de Informação e Comunicação utilizadas pelas principais empresas seguradoras do Brasil. Journal of Perspectives in Management $-J P M, 2(2)$, p. 51-65.

\section{Resumo}

As seguradoras, que compõe o setor de serviços, são vistas como grandes agentes econômicos. A participação do setor de seguros, no Brasil, deve chegar a 7,5\% do PIB e, por outro lado, ainda é pouco acessível à população no varejo, principalmente em função de seus custos. Paralelamente, as tecnologias de informação e comunicação (TIC) tem sido largamente utilizadas para inovar os negócios, organizações e sociedades, no sentido de ampliar serviços, reduzir custos, aumentar performance e alcance, bem como difundir informações. Nesse cenário, essa pesquisa busca recuperar essa discussão, apresentando benefícios e barreiras para adoção de serviços online. Para contextualizar a discussão, foram exploradas as plataformas digitais das cinco maiores seguradoras do Brasil, com o objetivo de investigar quais são as principais tecnologias da informação e comunicação utilizadas nos serviços online pelas maiores seguradoras no Brasil. Como contribuição está a discussão de temas como e-Business e e-Insurance no sentido de aprimorar serviços e baratear custos, permitindo difusão e ampliação do acesso de pessoas aos serviços securitários.

Palavras-Chave: e-Insurance, e-Business, TIC, Seguradoras, Seguro. 


\section{Introdução}

$\mathrm{O}$ setor de seguros proporciona serviços fundamentais ao funcionamento da economia, pois oferece cobertura de riscos para organizações, investimentos e indivíduos. Esse negócio se dá por meio da venda de apólices de seguros. No Brasil, a taxa de crescimento do produto interno bruto (PIB) depende muito fortemente da área de serviços e, nesse sentido, o serviço de seguros tem relevância. A previsão da Escola Nacional de Seguros (ENS, 2017) é de que até 2025 esse setor tenha participação de 7,4\% do PIB. Já no primeiro semestre de 2018, conforme Cilo (2018), o mercado de seguros cresceu 7,5\%. Ainda de acordo com o autor, apesar do crescimento do mercado, os seguros são realidade distante para boa parte da população, por exemplo, apenas $20 \%$ da frota de veículo circulante está protegida. Nesse sentido, como observou Pinto (2006), os seguros de massa no Brasil constituíam privilégio dos extratos superiores da classe média e só recentemente as seguradoras teriam destinado recursos mais expressivos à criação e comercialização de produtos populares.

A falta de acesso a esse serviço está relacionada ao conhecimento sobre a utilidade do seguro. Contudo, está mormente relacionada ao preço e, de acordo com Universia Knowledge Wharton (2013), ao próprio custo. Esses custos estão conexos, de acordo com essa matéria, às imposições de regulamentação, mas também à baixa renda do brasileiro e, inclusive a própria prática das corretoras que impõe barreiras ao uso de tecnologias da informação para distribuição do seguro, obrigando o cliente a buscar a loja física para compra do produto. Por exemplo, a matéria indica que $20 \%$ dos clientes aceitariam comprar uma apólice online, entretanto, apenas 1\% das compras eram feitas por esse canal em 2013. Nesse mesmo sentido, Odoyo e Nyangosi (2011) afirmaram que os avanços tecnológicos colocam a disposição de empresas de seguros e agentes as ferramentas para trazer novas economias e melhores serviços para os consumidores. A digitalização tornou possível processar e comunicar informações mais rapidamente, de forma mais barata, fácil e confiável.

Com esta compreensão, este artigo tem como objetivo investigar quais são as principais tecnologias da informação e comunicação (TICs) utilizadas nos serviços online pelas maiores seguradoras no Brasil.

Na sequência à introdução, o presente artigo será apresentado da seguinte forma: o segundo item apresentará o referencial teórico, que serve como embasamento para a presente pesquisa sobre a TI no setor de seguros. O terceiro, terá a metodologia utilizada, a classificação da pesquisa, a estratégia da pesquisa, o tipo de pesquisa, forma de coleta de dados e análise dos dados. No quarto capítulo terá apresentação dos dados, contendo a análise do uso de tecnologia pelas maiores seguradoras e a disponibilidade de serviços online. No quinto capítulo serão abordadas as considerações finais. Por fim, são apresentadas as referências utilizadas e que deram base ao trabalho e a pesquisa.

\section{Referencial Teórico}

Nesse referencial teórico primeiramente é apresentada uma revisão sobre as TICs de uma forma mais geral, buscando uma primeira motivação para avaliar as TICs como um elemento central nas organizações. $\mathrm{Na}$ sequência, discute-se a possibilidade de virtualização de serviços para aproximar-se as TIC empregadas em e-Business e $e$-Insurance para entrega de serviços online.

\subsection{As Tecnologias da Informação e Comunicação}

Investir em soluções baseados na Tecnologia da Informação (TI) tornou-se um desafio para os diversos setores da economia, incluindo o setor financeiro e de seguros, pois a evolução das ferramentas tecnológicas transformam, cada vez mais rapidamente, o ambiente e a dinâmica dos setores, promovendo a eficiência nos processos decisórios, nos processos organizacionais e a prestação de serviços ao cliente (Biagi, 2013).

Neste cenário, as Tecnologias da Informação e Comunicação (TICs) são relevantes para o desenvolvimento em função do seu poder transformador e estratégico na sociedade, governos, políticas públicas, movimentos sociais, organizações e indivíduos. Além disso, as mesmas podem democratizar a informação, solucionar problemas que afetam a humanidade, melhorar a gestão das organizações e cidades, ampliar a liberdade e as possibilidades de escolha entre outras (Diniz, 2010; Cunha \& Miranda, 2013; Coelho, 2014). 
É ainda um diferencial competitivo no gerenciamento das empresas, ONGs, governos, movimentos sociais e demais organizações. Portanto, a informação torna-se uma dimensão de poder e alteração social, condicionando não só modos de socialização e vida, lazer, trabalho, consumo, como também o sistema político e educacional (Castells, 2000).

Parece consenso que a vida de hoje é fortemente afetada pelas mudanças introduzidas através da emergência da informação e do conhecimento como aspectos fundamentais e determinantes da nova sociedade, levando a uma nova compreensão das organizações e suas dinâmicas de funcionamento (Audy, Andrade \& Cidral, 2005).

No âmbito social, econômico e político, na busca por conhecimento e integração entre as pessoas e equipamentos a Tecnologia da informação e comunicação (TIC) dispõe de diversas ferramentas para compartilhamento de dados e informações, sejam smartphones, notebooks, mídias sociais, internet, entre outras. O campo organizacional foi afetado diretamente no funcionamento dos processos, gestão de pessoas, aumento da produtividade e qualidade, capacidade de inovação de bens e serviços e na forma de conduzir o seu marketing.

Desse modo, inicialmente faz-se necessário esclarecer o que se compreende por TIC. De acordo com o Centro de Estudos sobre as Tecnologias da Informação e da Comunicação (CETIC, 2016), a TIC pode ser representada pela televisão, rádio, telefone fixo, console de jogo/videogame, TV por assinatura, antena parabólica, computador de mesa, computador portátil, e telefone celular. Essas tecnologias são consideradas pela pesquisa TIC Domicílios, realizada anualmente desde 2005, como sendo as tecnologias de informação, consideradas também como de comunicação, uma vez que intermediam as relações comunicacionais entre as pessoas. O principal objetivo da pesquisa citada é mapear o acesso à infraestrutura TIC nos domicílios urbanos e rurais do país e as formas de uso destas tecnologias por indivíduos de 10 anos de idade ou mais (CETIC, 2016).

Assim sendo, é possível conceituar TI como, de acordo com Audy, Andrade e Cidral (2005, p. 155):

[...] o conjunto de recursos não humanos empregados na coleta, armazenamento, processamento e distribuição da informação. Além disso, consideremos que a TI abrange os métodos, as técnicas e as ferramentas para planejamento, desenvolvimento e suporte dos processos de utilização da informação. Na atualidade o conceito de TI é utilizado para expressar a convergência entre a informática e as telecomunicações.

Ademais, comentamos que a TI está baseada em componentes como o hardware, software, sistemas de telecomunicações e gestão de dados e informações. Estes instrumentos, com o contato do ser humano acabam interagindo entre si. O homem não é parte da TI, mas sem sua existência, comando e direcionamento das execuções, tal tecnologia não teria sentido em existir.

Os principais instrumentos utilizados pela TIC, como já citados, são: os hardwares, softwares e os dispositivos de comunicação. Hardware se pode definir como a parte física da tecnologia, de forma tangível, sendo os equipamentos, máquinas e seus periféricos (placa de vídeo, processador, memória, etc.) que combinados formam os computadores, calculadoras, notebooks, entre outros. O termo hardware é usado para fazer referência a detalhes específicos de cada equipamento, incluindo informações detalhadas sobre seus componentes, seu funcionamento, suas restrições e potencialidades (Tanenbaum \& Zucchi, 2009).

Os softwares são responsáveis pelos comandos a serem executados pelos dispositivos, uma parte lógica da tecnologia, podendo ser aplicativos simples de celulares até mesmo a programas e programações complexas existentes em computadores e máquinas nas diversas organizações mundo afora.

Atualmente, grandes empresas possuem ao menos alguns softwares básicos executáveis em seu ambiente, como um sistema operacional ou programa de cadastro de clientes, mas com o passar dos anos e desenvolvimento de novos sistemas, cada vez mais são criadas novas plataformas que buscam auxiliar no gerenciamento das organizações, na sua parte operacional e no fornecimento de dados para o controle da mesma. Com isso, muitos programas foram criados e são direcionados para funções especificas em setores previamente combinados de determinadas empresas. 
A rede de comunicação é o conjunto que possibilita a existência de um sistema de informação, onde tais, usando dos artifícios das tecnologias da comunicação, cumprem seus objetivos e funções. Podemos destacar como mais importante na comunicação às redes de telecomunicações, formadas pelos hardwares e softwares que estabelecem a ligação entre um emissor e receptor através de diferentes sinais e ainda a rede de computadores, que visa melhorar a comunicação e transmissão de informações através de diferentes tipos de redes. A contribuição da tecnologia da informação nas telecomunicações é de suma importância, pois contribuem para as empresas romperem barreiras geográficas, temporais e estruturais.

Um outro meio de comunicação que revolucionou na história da TI foi sem dúvida a internet, uma rede mundial de informações com milhões de sistemas e usuários. Existem vários canais de comunicação para vários meios de comunicação, para interligar os componentes que fazem parte do sistema de comunicação o hardware e software devem estar interligados. Neste sentido, para Padoveze (2015), o conceito de tecnologia da informação abrange a informação (seus sistemas, recursos etc.) como parte de uma estrutura em nível estratégico das empresas.

A TI é um fator importante de competitividade, não deve ficar restrita apenas as necessidades internas da empresa, mas também ser usada nas atividades externas, com clientes, fornecedores ou concorrentes. Pode-se verificar que a TIC cada vez mais exerce uma função de extrema importância nas organizações, fornecendo base para as decisões, e é observada de uma forma diferente pelos gestores. "A tecnologia da informação não é simplesmente útil, viabilizadora, mas sim o cerne da empresa, a ferramenta primordial de administração" (Laudon \& Laudon, 2007, p. 6).

É possível, portanto, constatar que o setor de tecnologia também promove diversas oportunidades como produtos inovadores, expansão dos negócios, redução de custos, dinamicidade, flexibilidade dentre outros.

A TI está sendo utilizada para proporcionar uma oportunidade de crescimento, melhoria na tomada de decisão, perfil e hábito dos seus clientes (Silva, 2007), por isso Guissoni (2017, p. 26) afirma que:

Com a integração das lojas à internet, redes sociais e aplicativos em vários dispositivos, é possível atingir um estágio mais avançado do customer analytics e obter maior retorno no negócio. O sistema conhecido como cookie tracking, por exemplo, permite monitorar a navegação de usuários a partir do endereço IP e relacioná-la com dados demográficos, geográficos e comportamentais de cada pessoa. Os smartphones desempenham um importante papel na obtenção de dados, já que a navegação na internet nesses dispositivos móveis também pode ser monitorada pelo sistema de cookies. No Brasil, a penetração de smartphones aumentou de 7\% em 2011 para 43\% em 2016.

Partindo deste entendimento, a TI é uma grande força para as seguradoras pois com essa ferramenta se torna factível transformar dados em informação de forma holística, permitindo facilidade em suas decisões. Porém, as seguradoras ainda se mostram distantes do grande público. A maior parte delas, só agora começa a se dar conta de que ampliar o relacionamento com o segurado passou a ser estratégico. Ele deve ser encarado como o principal elo da cadeia produtiva. As que ainda priorizam o produto em detrimento do cliente começam a perder espaço no mercado. A grande maioria dos consumidores insatisfeitos reclama cada vez menos da qualidade dos serviços prestados; simplesmente deletam o nome da empresa da lista de fornecedores (Pinto, 2006).

O mercado cada vez mais competitivo acaba forçando as seguradoras a buscarem novos mecanismos que agilizem esse processo de relação com os consumidores, sobretudo virtualizar os serviços e intensificar o uso das TIC's na oferta, negociação, fechando e manutenção dos serviços securitários.

\subsection{Virtualização dos Serviços: Vantagens e Desvantagens}

Overby (2008) discute sobre a virtualização de processos, procurando avaliar a factibilidade do processo de virtualização em função de requisitos de necessidades de interação física. Quanto menos requisitos um processo apresentar mais facilmente ele pode ser virtualizado. As TICs, nesse sentido, têm recursos de representação, alcance e monitoramento que moderam os requisitos de virtualização e podem 
facilitar o processo de virtualização. No quadro 1 é possível analisar as características de um serviço físico comparativamente a um virtual.

Quadro 1: Comparação entre serviços físicos e virtuais.

\begin{tabular}{|c|c|c|}
\hline Características & Serviço virtual & Serviço físico \\
\hline Encontro do serviço & Na tela & Pessoalmente \\
\hline Disponibilidade & Toda Hora & Horário comercial padrão \\
\hline Acesso & Em casa & Ida até o local \\
\hline Área de mercado & Internacional & Local \\
\hline Ambientação & Iterface eletrônica & Ambiente físico \\
\hline Diferenciação competitiva & Conveniência & Personalização \\
\hline Privacidade & Anonimato & Interação social \\
\hline
\end{tabular}

Fonte: Fitzsimmons e Fitzsimmons (2011).

No quadro 2 ainda é possível observar as vantagens e dificuldades de se comprar em uma loja online ou em uma tradicional. Mesmo com a evolução da tecnologia a forma tradicional ainda representa grande parte do comércio.

Quadro 2: Vantagens e desvantagens entre serviços físicos e virtuais.

\begin{tabular}{|c|c|c|}
\hline & Compra online & Compra em loja tradicional \\
\hline Vantagens & $\begin{array}{c}\text { Conveniência } \\
\text { Economia de Tempo } \\
\text { Reduz as compras por impulso }\end{array}$ & $\begin{array}{c}\text { Os cinco sentidos influenciam a compra } \\
\text { Ativa a recordação } \\
\text { Amostra do produto } \\
\text { Exposição de novos itens } \\
\text { Interação social }\end{array}$ \\
\hline Desvantagens & $\begin{array}{l}\text { Menor controle de preço e seleção } \\
\text { Esquecimento de itens } \\
\text { Dependência do computador } \\
\text { Taxa de Entrega }\end{array}$ & $\begin{array}{c}\text { Consumo de Tempo } \\
\text { Filas de espera e estacionamento } \\
\text { Transporte dos itens } \\
\text { Compra por impulso } \\
\text { Segurança }\end{array}$ \\
\hline
\end{tabular}

Fonte: Fitzsimmons e Fitzsimmons (2011).

E como abordado, a TI tem papel fundamental nessa mudança de situação ao impor efeitos sobre as interfaces entre clientes e fornecedores (Francisco, Kugler \& Larieira, 2017).

\section{3 e-Business e $e$-Insurance}

E-business é um termo recente, cunhado inicialmente pela IBM nos anos 90, que se refere a negócios altamente conectados, estabelecendo assim uma ligação direta entre negócios e Internet. Desde então, o conceito ganhou várias dimensões na literatura, e tornou-se um termo 'guarda-chuva', no sentido de que engloba outros conceitos tais como e-commerce e e-government (Amit e Zott, 2001; Laudon \& Laudon, 2007; Morais et al, 2012).

A utilização dos e-business gera diversos tipos de benefícios já estudados pela literatura e percebidos pelas empresas, como maior integração dos sistemas, integração com clientes e parceiros de negócio, maior velocidade nas informações, maior transparência, maior performance dos negócios e novas oportunidades. 
Vários autores encontraram (ou sugeriram) correlação entre adoção de e-business e performance da empresa (Laudon \& Laudon, 2007; Boateng et al., 2008; Raymond e Bergeron, 2008).

Sob o guarda-chuva do e-Business também está o conceito de E-Insurance, ou também chamado de serviços de seguros na Internet, que é definido como serviços de vendas de seguros, serviços e sites de informações fornecidos on-line. O e-Insurance está relacionado, portanto, como a aplicação de internet e outras tecnologias da informação (TI) para a produção e distribuição de serviços de seguros. Em um sentido mais restrito, pode ser definido como a prestação de uma cobertura de seguro em que uma apólice de seguro é solicitada, oferecida, negociada e contratada online (Khandare \& Ingle, 2017).

De acordo com Pinto (2006) na atualidade as seguradoras mais atentas já estão promovendo verdadeira guerra ao papel, procurando facilitar a vida de corretores e clientes. Algumas já processam eletronicamente grandes volumes de propostas, o que redunda em maior eficiência operacional e contribui para reduzir a percepção, muito difundida entre os segurados, de que persiste acentuada afinidade entre seguro e burocracia.

\subsubsection{Beneficios e Barreiras do e-Insurance}

Khandare e Ingle (2017) falam de 6 categorias de benefícios do $e$-Insurance, sendo elas:

\footnotetext{
Diretos: São aqueles quantificáveis, como o número de novos clientes por canais eletrônicos.

Indiretos: Não mensuráveis facilmente, como aumento da lealdade do cliente como resultado dos serviços online

Curto Prazo: Aqueles que se realizam no prazo de meses, como aumento de receitas e produtividade

Longo Prazo: Formação de novas redes de contatos, vendas e operação

Tangíveis: redução de custos para coletar, armazenar, recuperar, processar, analisar e transmitir informações. Novas técnicas de Marketing por meios digitais

Intangíveis: melhoria da relação com parceiros

Miscelânea: Melhora capacidade distribuir informações e acesso de clientes aos seus contratos, acelera a preparação de propostas e conclusão de contrato on-line, notificação de reclamações e relacionamento com cliente.
}

Todos esses benefícios, ainda de acordo com os autores, podem ser divididos de forma mais sucinta em apenas duas categorias: os informacionais e os operacionais. Os autores também avaliam benefícios para economia nacional, como aumento do PIB, e benefícios em nível sócio-cultural, como desenvolver a consciência sobre a importância dos seguros (Khandare \& Ingle, 2017).

Como barreiras os autores indicam aquelas relacionadas a finanças (custos para adotar as TIC), segurança (vírus e privacidade), técnicas (complexidade das TIC exige grande conhecimento nessa área), de gestão (gerentes não tem tempo suficiente para planejar estrategicamente a adoção e uso das TIC). A complexidade de alguns seguros também não permite fácil compreensão pela internet e podem exigir canal de atendimento. Além disso, como observam os autores, embora a compra do seguro possa ser feita como qualquer outra compra via e-commerce (pesquisa, avaliação, contato, compra e pós venda), deferentemente de outras transações no e-commerce, a comunicação e liquidação de sinistro podem envolver autoridades legais, como registro na delegacia de polícia, entre outros (Khandare \& Ingle, 2017).

\section{Abordagem Metodológica}

A pesquisa se deu através de um estudo exploratório descritivo em sites das seguradoras, com o escopo de identificar quais são as mais recentes ferramentas de TI utilizadas pelas corporações securitárias.

O estudo exploratório é normalmente considerado por alguns autores como o passo inicial no processo de pesquisa pela experiência e auxílio, pois, proporciona maiores informações sobre determinados assuntos (Cervo \& Bervian, 1996). 
Para avaliar como e-Insurance é constituído e entregue nas plataformas digitais, investigou-se os serviços ofertados no ramo de seguro do automóvel por meio de coleta e análise de dados secundários. Foram analisadas as plataformas digitais na internet dos sites das cinco maiores seguradoras que atuaram no Brasil em 2017 (Valor, 2018), a saber Bradesco, Sul América, BB e Mapfre, Porto Seguro e Caixa Seguros. O Ranking é elaborado anualmente pelo jornal Valor.

\section{Análise dos Dados}

A seguir os dados coletados nos sites são apresentados em função das TICs utilizadas. São apresentados serviços entregues via aplicativos de celular, e-mail, chat online e chatbot, bem como SEO e redes sociais.

\subsection{Aplicativos usados para Vistoria}

Um exemplo mais recente é o aplicativo desenvolvido pela Porto Seguro, que tem por objetivo promover a realização de vistoria prévia. A vistoria prévia é a inspeção que a seguradora realiza, antes da aceitação do risco, para verificação das características e do estado de conservação do veículo (PORTO SEGURO, 2018).

O objetivo é proporcionar mais agilidade na realização da vistoria para clientes que moram em regiões mais afastadas das regiões centrais, eles poderão contar com o aplicativo de Vistoria Prévia da Porto Seguro para que eles efetuem a vistoria de seu veículo. Isso atesta empiricamente a TI como cerne do processo empresarial, plenamente vinculada a estratégia corporativa como Laudon e Laudon (2007) já sinalizavam.

Figura 1: Aplicativo de vistoria prévia.

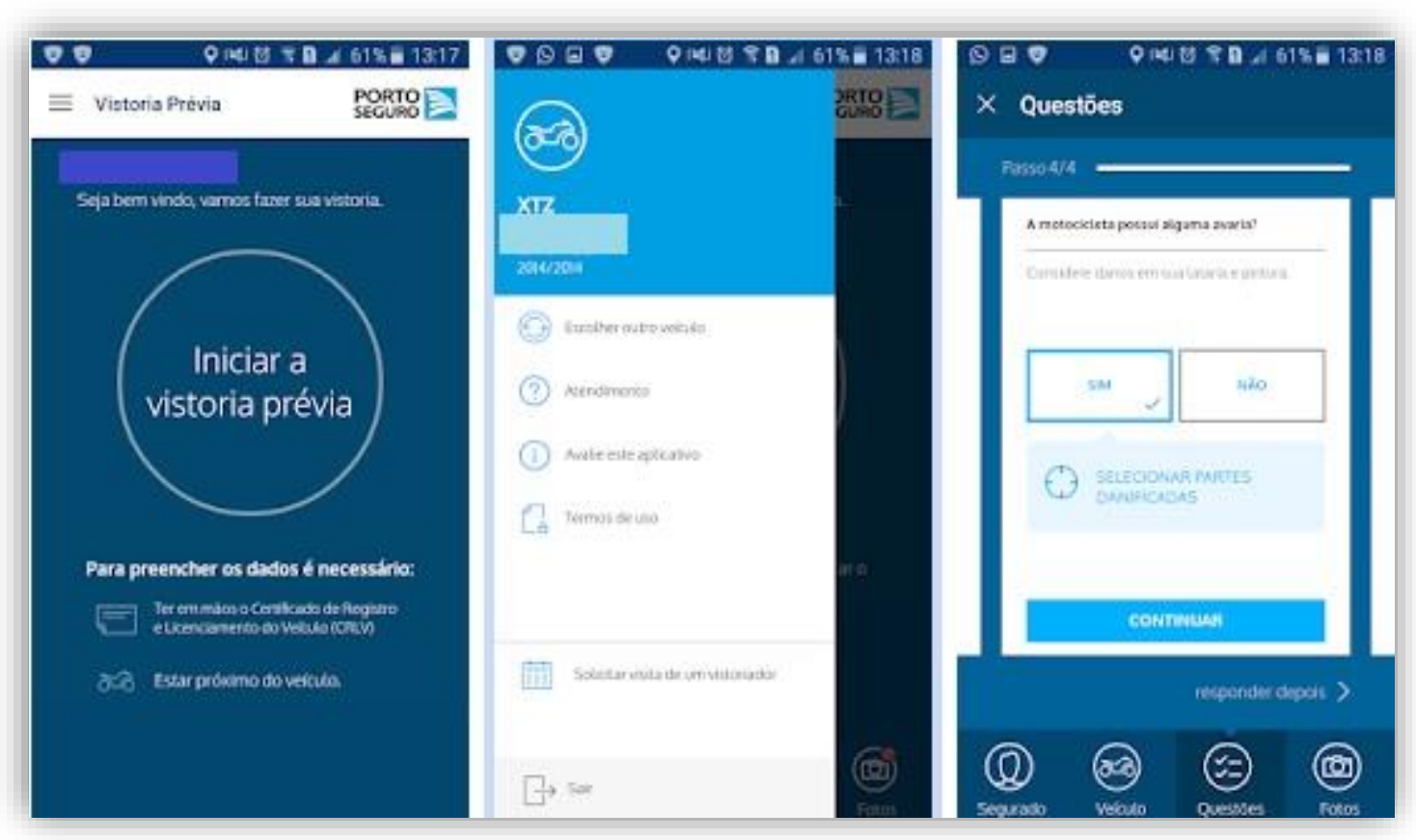

Fonte: App Porto Seguro, adaptado pelos autores (2018).

Como se pode observar na figura 1 o aplicativo apresenta funcionalidades que podem ser preenchidas pelo cliente. 
Outro exemplo identificado é a MAPFRE Seguros (figura 2), que assim como outras seguradoras também possui seu aplicativo para smartphones. Com o novo aplicativo MAPFRE, você poderá contar com o envio de socorro, solicitar o guincho e poderá agilizar a análise do processo enviando as fotos dos danos do acidente. Tudo de maneira simples e rápida (MAPFRE, 2018).

Figura 2: Aplicativo de Assistência MAPFRE Seguros.

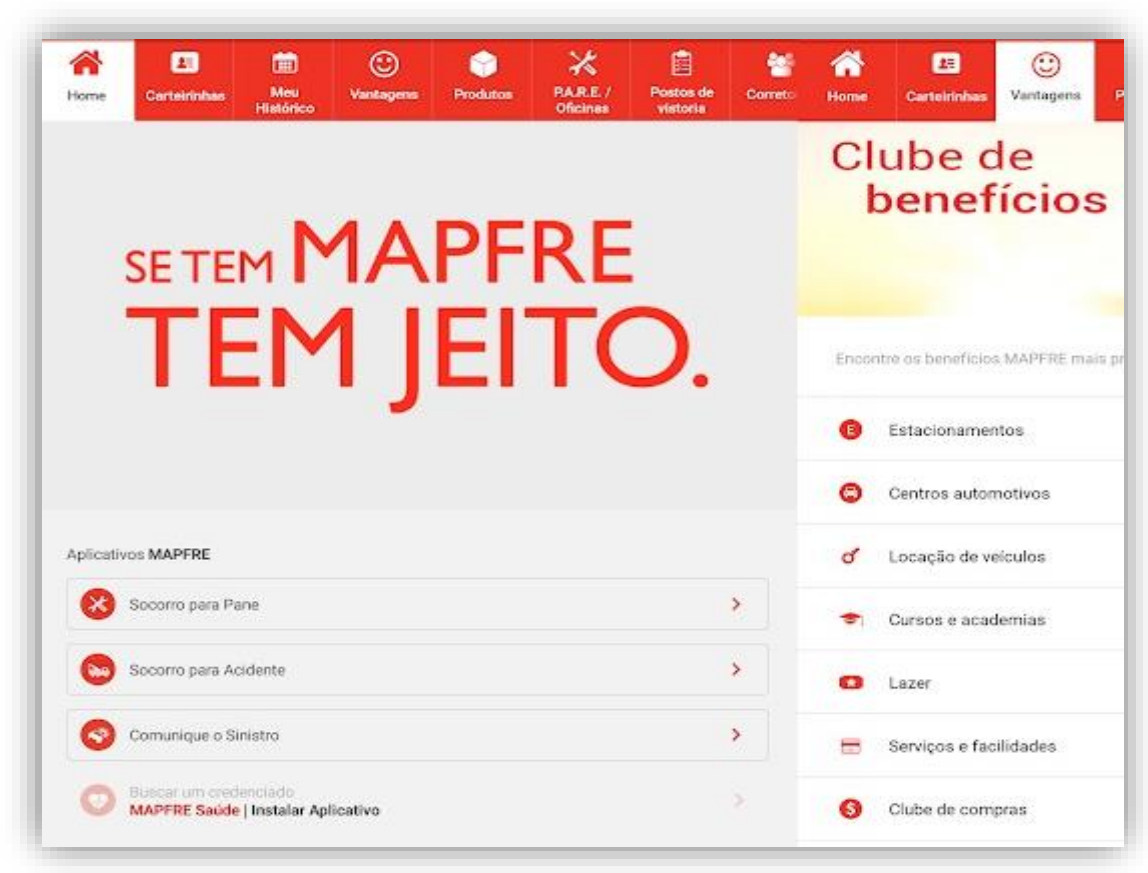

Fonte: App MAPFRE, adaptado pelos autores (2018).

Com relação ao serviço de vistoria, no ramo de automóvel, por exemplo, a seguradora tinha seus próprios peritos de vistoria prévia, tornando-se um custo alto avaliando de forma global, pois era necessário contratar peritos em regiões interioranas onde a demanda não correspondia aos custos de manter os mesmos. Com a terceirização, este serviço iniciou-se uma nova fase para as seguradoras, reduzindo custos e aumentando sua base de segurados. Com o advir dos anos e a percepção dos resultados positivos com a vistoria prévia, terceirizou-se também a vistoria de sinistro, onde novamente foi favorecida principalmente por menores custos e ainda agilidade em atendimentos aos segurados. Atualmente com o aplicativo, a inovação alterou ainda mais este serviço, reduziu custo, ofereceu flexibilidade e comodidade.

\section{2 e-mail para emissão de Apólice e Cartão}

Observa-se que no ramo de seguros um dos produtos mais experimentados são emissões das apólices e os cartões dos segurados, ou carteirinha do seguro. Durante muito tempo a confecção e envio de tais documentos era bastante comum e custoso para o cliente, que era cobrado uma taxa na contratação do seguro, justamente para arcar com tais custos. Sem falar dos custos ambientais, pois as seguradoras enviavam verdadeiros livros, com todas as condições gerais, clausulas detalhadas, além do cartão de plástico com identificação do cliente e números para contato. Essa prática já vem caindo em desuso, não se cobrando mais valor para emissão e envio da apólice e cartões. As empresas passaram a disponibilizar um resumo da apólice e um cartão de modo online nos celulares.

Constatou-se que a partir de 2016 muitas seguradoras não estão mais enviando a via física, apenas por e-mail ou permitindo a consulta pelo site e no aplicativo do celular. Facilita a consulta, evita impressões e fica disponível constantemente, na tela do computador ou na palma da mão em um smartphone. 
Já na figura 3 pode-se observar a via digital do cartão do segurado, com as informações e telefones de contato em caso de necessidade. Muitos clientes ainda preferem manter a via física e algumas seguradoras enviam das duas formas, porém outras como a Sul América passaram a somente enviar a apólice impressa após solicitação do segurado. Tais documentos geram um custo para as empresas, mesmo que baixos, mas além da confecção existe o valor do envio.

Figura 3: Cartão do Segurado.

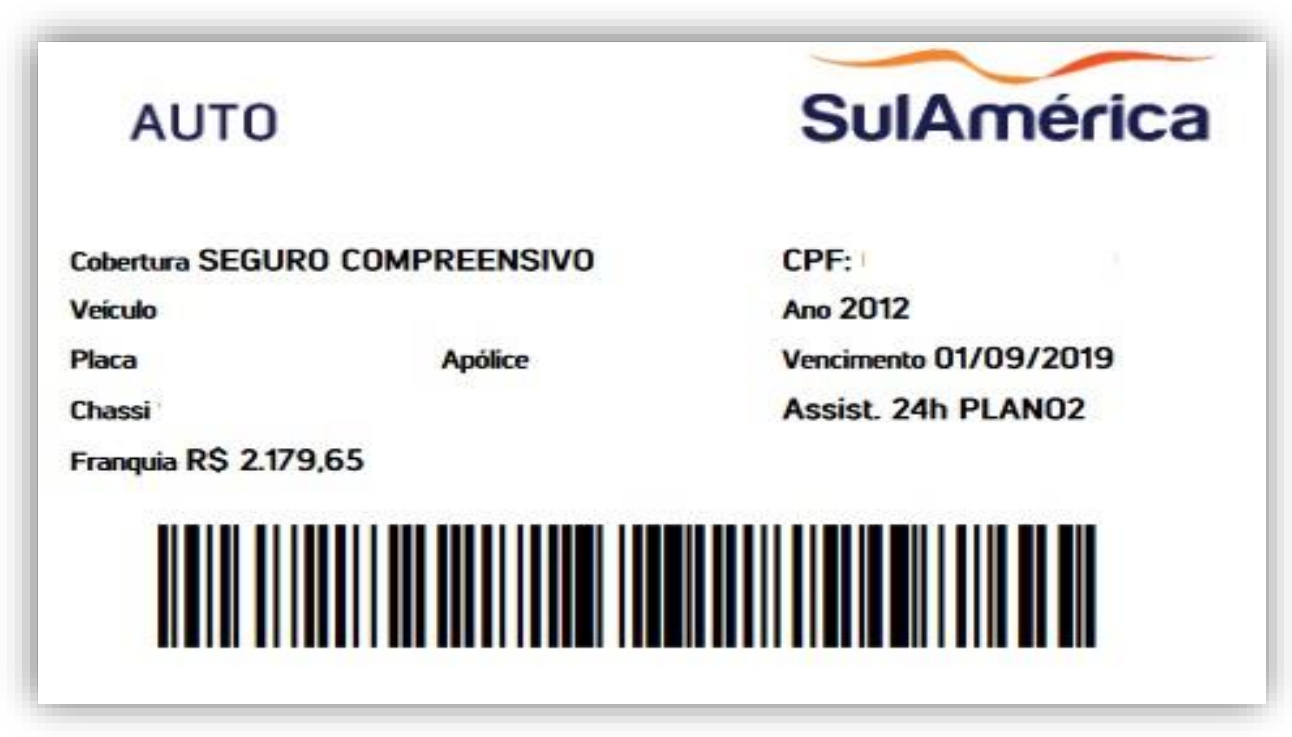

Fonte: adaptado pelos autores (2018).

Como se pode observar o cartão do segurado contém todas informações essenciais sobre o segurado e os dados do veículo (figura 4).

Figura 4: Envio de apólice por e-mail.

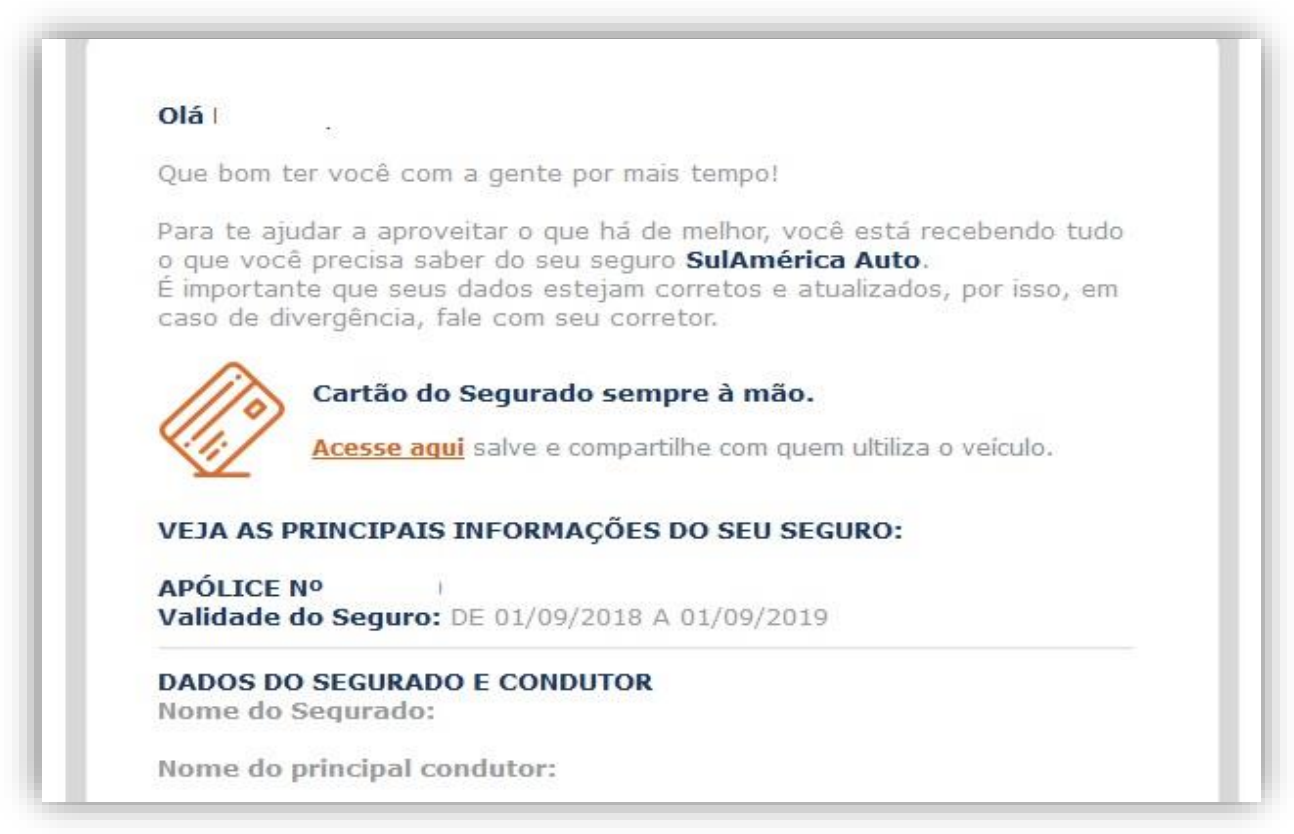

Fonte: adaptado pelos autores (2018). 


\subsection{Chat e Chatbot para atendimento}

Outro instrumento que passou a ser utilizado pelas grandes corporações de seguros é o chatbot (figura 5 e 6). Chatbots são "robôs" que fazem a função específica de chat ou diálogo. São comumente utilizados pelas empresas para marketing, relacionamento e comunicação com os clientes. Abaixo temos exemplos do chatbot da Caixa Seguradora e do chatbot corretor da Bradesco Seguros.

Figura 5: Chatbot da Caixa Seguradora.

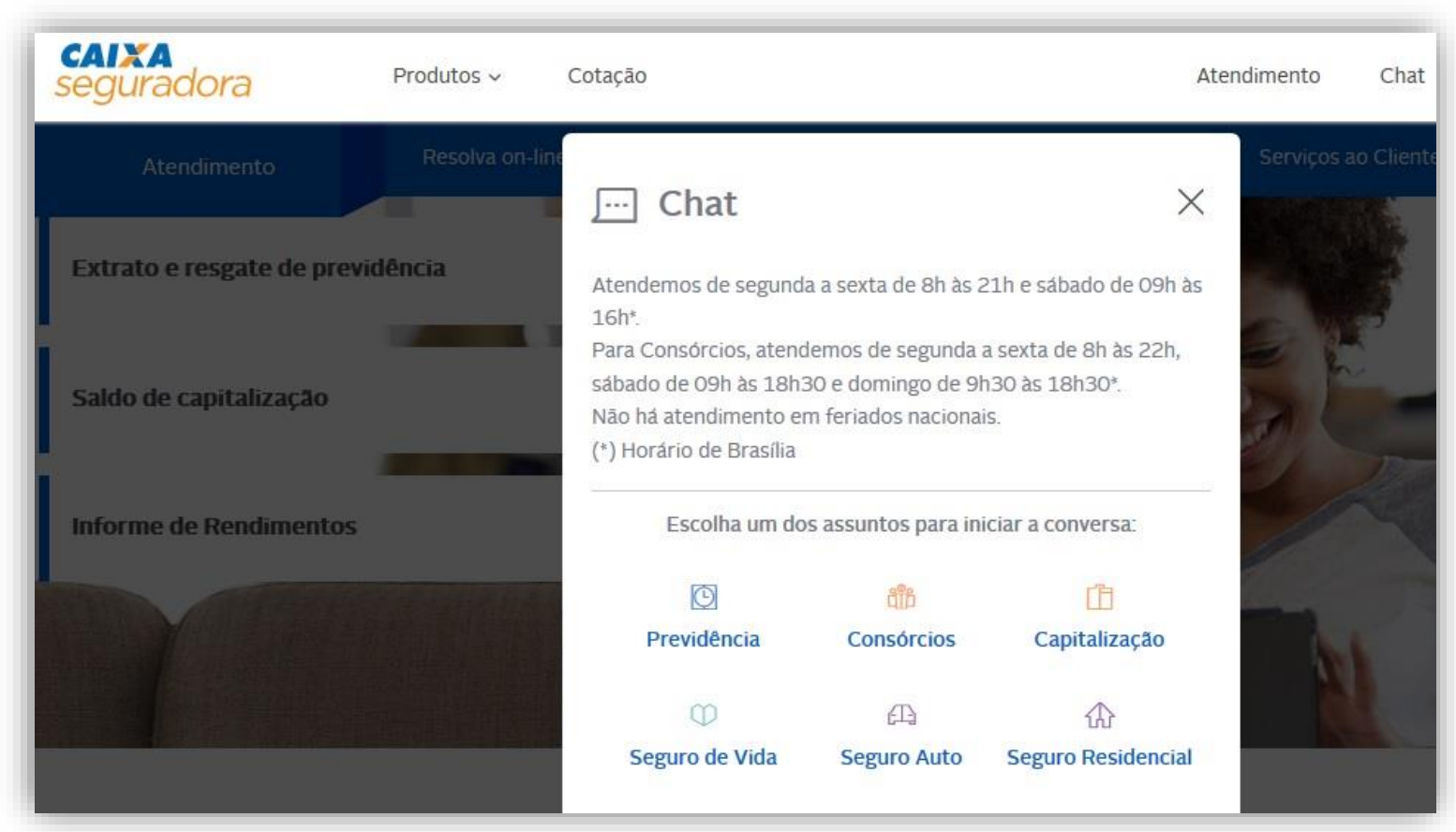

Fonte: adaptado pelos autores (2018).

Figura 6: Tela inicial do chat de atendimento Bradesco Seguros.

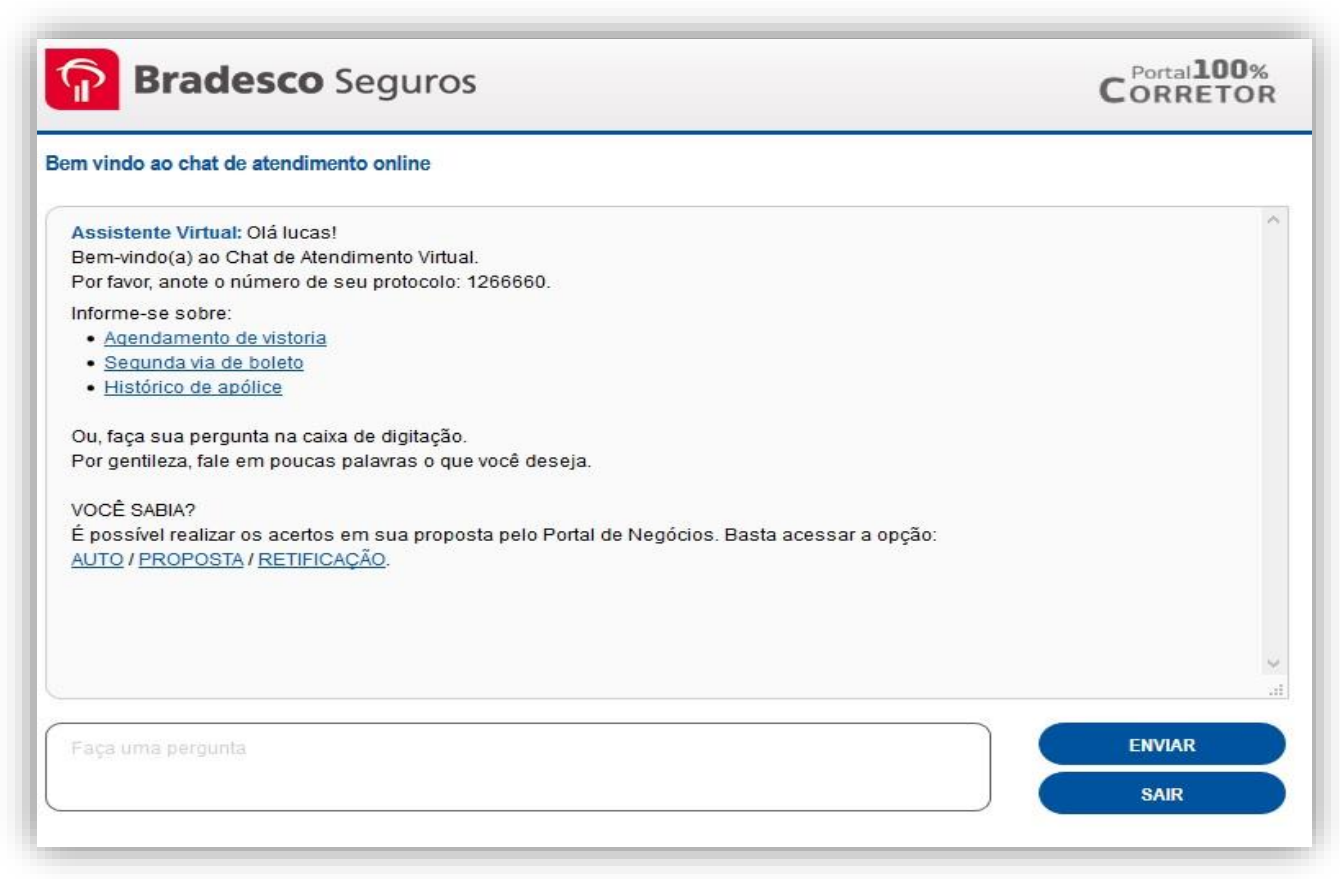

Fonte: adaptado pelos autores (2018). 
Após esse primeiro contato com um atendente virtual, ele oferece para o usuário algumas opções para resolução do problema ou apresenta respostas para algum questionamento. Por ser uma máquina do outro lado, a sistemática consiste numa relação entre palavras chaves, portanto, ao digitar uma única palavra ela irá me oferecer várias opções relacionadas aquele assunto. E mesmo se com a ajuda de um atendimento virtual o problema não for resolvido ele me dá a opção de um contato personalizado com um atendentehumano. Como segue no exemplo descrito na figura 7.

Figura 7: Atendimento humano.

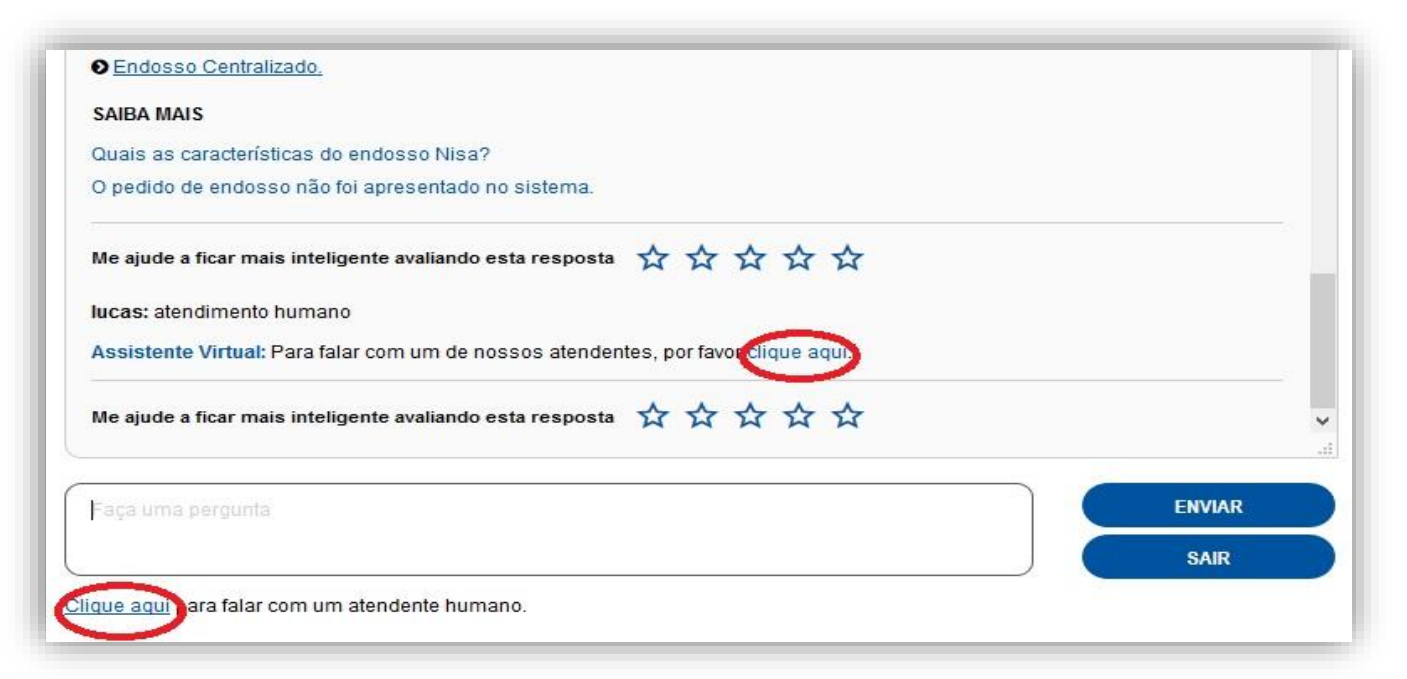

Fonte: Adaptação própria, 2019.

O principal objetivo dessas implementações pelas seguradoras, tanto os aplicativos para atendimento, os chatbots, o aplicativo de vistoria, são para dar maior agilidade ao processo de prestação de serviço, ganhando em escala territorial, em tempo e redução de gastos. Um grande período de tempo é economizado se os clientes não precisarem esperar filas para atendimento ou ter que se deslocar para realizar uma vistoria. Isso sem falar na economia de despesas, tendo em vista que um chatbot pode realizar vários contatos simultâneos.

\subsection{SEO, Redes Sociais e Aplicativos de Mensagens Instantâneas para serviços informacionais}

Ferramentas de marketing digital também são facilmente encontradas na realidade das seguradoras. Abordando um primeiro exemplo, temos aqui o da Porto Seguro com o Search Engine Optimization ou SEO, onde este apresenta as mais variadas funções, como pesquisa de palavras-chave, otimização de websites por meio de plugins e análises. Nesse caso, especificamente, é utilizado no site da seguradora, como verifica-se a seguir.

Nesse caso, ao realizar uma busca por uma só palavra, o site acaba oferecendo diversas opções relacionadas aquela palavra digitada ou ao tema. Ao escrever Auto, são oferecidas opções de automóveis, autoatendimento, apólice auto, entre outras.

Outro exemplo é da ferramenta de monitoramento de redes sociais. Esse sistema estimula o ganho de produtividade por meio do pré-agendamento de postagens, possibilita fazer um acompanhamento das menções à marca e avaliar o engajamento e resposta aos conteúdos e à base de seguidores. No caso da Sul América, o Facebook ${ }^{\circledR}$ da empresa realiza diversas postagens ao longo do dia, sendo uma das seguradoras que mais interage com os internautas (figura 8). Isso possibilita que ela esteja sempre divulgando algo para seu grande número de seguidores. 
Figura 8: Palavras chaves da pesquisa no site Porto.

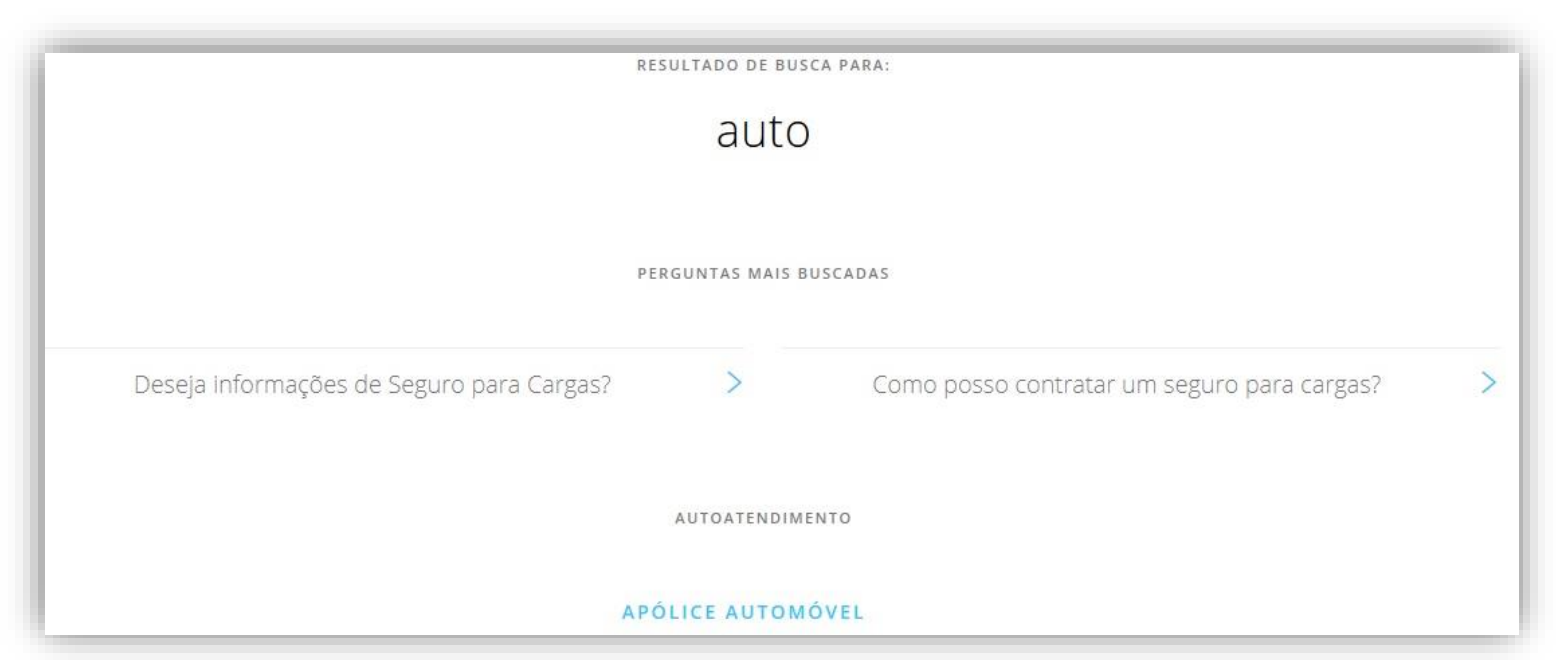

Fonte: Adaptação própria, 2019.

\section{Considerações Finais}

Atualmente o ramo de seguros possui uma grande importância na economia de um país, pois é por meio desse que muitas organizações e pessoas preparam-se para eventos inesperados. Alguns desses eventos são assaltos, desastres ambientais, problemas do clima, acidentes, incêndios, entre uma infinidade de ocorrências que, se não estiverem cobertas por um seguro, acabam colocando em risco o patrimônio dos envolvidos.

Esse artigo buscou identificar benefícios e barreiras envolvidos no e-Insurance, ou seja, nos serviços online oferecidos pelas seguradoras, tanto para companhias de seguro, em vários termos, como para pessoas e para economia nacional. Também foi discutido o tema da virtualização de serviços, tópico no qual foram listadas características, benefícios e dificuldades envolvidas em serviços online. A entrega dos serviços online foi avaliada nas plataformas digitais de cinco maiores seguradoras no Brasil a fim de possibilitar a discussão e apresentar quais ferramentas estão disponíveis e em uso. Nota-se que pelo próprio site é possível fazer pedidos de cálculos, pesquisar telefones das seguradoras, fazer reclamações e elogios. A presença nas redes sociais é mais um fator que passou a ser melhor utilizada pelas empresas. Pelo Facebook ou Instagram é possível ver dicas sobre seguros e também fazer comunicações com a empresa.

O próprio processo de fechamento de contrato foi modificado por conta da tecnologia. Clientes não precisam mais se dirigir até o prédio, um contrato pode ser fechado via ligação ou até mensagem pelo WhatsApp. Resolução de sinistros também se tornaram mais rápidas por conta do uso da TI no acompanhamento desses processos

Pedidos de assistência por aplicativos, realização de vistorias no celular, atendimento robotizado, exclusão de papéis impressos, todos esses são exemplos de mudanças provocadas pela aplicação da TI pelas companhias securitárias.

A problemática abordada conserva a relevância, observada pelo aumento do uso da tecnologia nas organizações de todos os setores. O serviço ofertado tanto pelas seguradoras e corretores foi modificado com a evolução da tecnologia. Papéis, presença física, burocracia, lentidão e pouca diversificação praticamente não existem mais. Se observa hoje um ambiente muito mais favorável para atuação das seguradoras e dos corretores. Também para os clientes, que tem formas mais eficientes para conhecer aquilo que estão contratando.

Como sugestão de investigação futura sugere-se ampliar a amostra de plataformas digitais visitadas, permitindo comparações, bem como aprofundar no tema de novas organizações securitárias que surgem a partir da aplicação intensiva das TIC nos negócios securitários, geralmente startups tecnológicas que visam resolver problemas específicos e oferecer atendimentos de nicho, chamadas de "Insurtech". 


\section{Referências}

Amit, R., \& Zott, C. (2001). Value creation in e-business. Strategic Management Journal, 22(6), p. 493-520.

Audy, J. L. N., Andrade, G. K., \& Cidral, A. (2009). Fundamentos de sistemas de informação. Bookman editora.

Biagi, F. (2013). ICT and Productivity: A Review of the Literature. Institute for Prospective Technological Studies. Digital Economy Working Paper 2013/9. Disponível online: https://pdfs.semanticscholar.org/1c85/219b3f962cb8f9884ec93a4c8e2556ed5fc7.pdf. Acesso em 1 fev. 2019.

Boateng, R., Heeks, R., Molla, A. \& Hinson, R. (2008). E-commerce and socio-economic development: conceptualizing the link. Internet Research, 18(5), p. 562-594.

Brasscom. (2014). Desoneração da Folha de Pagamento e Competitividade em TI. Associação Brasileira das Empresas de Tecnologia da Informação e Comunicação Disponível em: https://brasscom.org.br/wpcontent/uploads/2016/12/Brasscom-DOC-2014-001-v34.pdf. Acesso em: 7 abr 2018.

Castells, M. (2000). A era da informação: economia, sociedade e cultura. In Castells, M. (2000). A Sociedade em rede. São Paulo: Paz e Terra.

CERT.br. (2012). Cartilha de Segurança Para Internet. 2012. Disponível em: https://cartilha.cert.br/livro/cartilha-seguranca-internet.pdf. Acesso em 1 fev. 2019.

Cervo, A. L., \& Bervian, P. A. (1996). Metodologia cientifica. São Paulo: Prentice Hall.

Cetic (2016). Pesquisa sobre o uso das tecnologias de informação e comunicação nos domicílios brasileiros : TIC domicílios $2016=$ Survey on the use of information and communication technologies in brazilian households : ICT households 2016 [livro eletrônico] / Núcleo de Informação e Coordenação do Ponto BR [editor] -- São Paulo -- Comitê Gestor da Internet no Brasil, 2

Cilo, N. (2018). Promissor, mercado de seguros cresce e se diversifica no país. Correio Brasiliense.

Disponível em <

https://www.correiobraziliense.com.br/app/noticia/economia/2018/08/28/internas_economia,702357/merc ado-de-seguros-cresce-e-se-diversifica-no-pais.shtml> Acessado em Dezembro/2018.

Claro, A. (2013). Sistemas de Informações Gerencias. São Paulo: Know How.

Coelho T. R. (2014). ICT4D: A inovação e o desempenho na perspectiva das capacidades de Sen.

Dissertação de Mestrado. Universidade Federal do Paraná (UFPR). Disponível em:

https://acervodigital.ufpr.br/bitstream/handle/1884/34944/R\%20-\%20D\%20\%20TAIANE\%20RITTA\%20COELHO.pdf?sequence=1. Acesso em 18 abr 2018.

Costa, A. D. S. C., Santana, L. C. D., \& Trigo, A. C. (2015). Qualidade do atendimento ao cliente: um grande diferencial competitivo para as organizações. Revista de Iniciação Científica-RIC Cairu, 2(2), p. 155-172.

Cruz, T. (2000). Sistemas de informações gerenciais: tecnologias da informação e a empresa do século XXI. Editora Atlas SA.

Cunha, M. A. V. C. D., \& Miranda, P. R. D. M. (2013). O uso de TIC pelos governos: uma proposta de agenda de pesquisa a partir da produção acadêmica e da prática nacional. Organizações \& Sociedade, 20(66), p. 543-566.

Diniz, E. H. (2010). Correspondentes bancários e microcrédito no Brasil: tecnologia bancária e ampliação dos serviços financeiros para a população de baixa renda. Relatório GVPesquisa. Disponível em: http://bibliotecadigital.fgv.br/dspace/bitstream/handle/10438/13365/EduardoDiniz\%20correspondentes\% 20e\%20microcredito.pdf?sequence=2\&isAllowed=y. Acesso em: 1 fev. 2019.

Duarte, R. (2002). Pesquisa qualitativa: reflexões sobre o trabalho de campo. Cadernos de pesquisa, 115, p. 139-154.

ENS - Escola Nacional de Seguro. (2017). A arrecadação de seguros pode chegar a 7,4\% do PIB em 2025. Disponível em: http://www.ens.edu.br/noticia-detalhes/arrecadacao-de-seguros-pode-chegar-a-74-do-pi. Acesso em 8 dez. 2018.

Fitzsimmons, J. A., \& Fitzsimmons, M. J. (2014). Administração de Serviços: Operações, Estratégia e Tecnologia da Informação. Amgh Editora.

Francisco, E. D., Kugler, J. L., \& Larieira, C. L. (2017). Líderes da Transformação Digital. GVEXECUTIVO, 16(2), p. 23-26.

Guissoni, L. A. (2017). Omnichannel: uma gestão integrada. GVExecutivo, 16(1), $24-27$.

Khandare, M. A., \& Ingle, A. (2018). Scope of internet advertising as part of ICT in the Insurance Sector (Einsurance). International Journal of Scientific Research, 6(5). 
Laudon, K. C. \& Laudon, J. P. (2007). Sistemas de informação gerenciais. São Paulo: Pearson Prentice Hall.

Morais, E. P., Pires, J. A. \& Gonçalves, R. M. (2012). E-business maturity: constraints associated with their evolution. Journal of Organizational Computing and Electronic Commerce, 22, p. 280-300.

Odoyo, F. S., \& Nyangosi, R. (2011). E-Insurance: an empirical study of perceived benefits. International Journal of Business and Social Science, 2(21).

Overby, E. (2008). Process virtualization theory and the impact of information technology. Organization Science, 19(2), p. 277-291.

Padoveze, C. L. (2015). Sistemas de Informações Contábeis: fundamentos e análise. 7 ed. São Paulo: Atlas.

Pinto, M. R. F. (2014). Estratégia competitiva no mercado de seguros: estudo de caso na cia Marítima Seguros SA. Monografia Ciências Contábeis. Universidade Federal De Santa Catarina (UFSC).

Porto Seguro. (2018). Central de Dúvidas e Atendimento a Clientes. Disponível em: http://atendimento.portoseguro.com.br/consulta-de-cliente/vistoria-pelo-app/. Acesso em: 22 mar 2018.

Raymond, L., \& Bergeron, F. (2008). Enabling the business strategy of SMEs through e-business capabilities: A strategic alignment perspective. Industrial Management \& Data Systems, 108(5), p. 577595.

Revista Apólice (2018). Prioridades em TI no mercado de seguros. Disponível em: https://www.revistaapolice.com.br/2017/09/ti-seguros-prioridades/. Acesso em: 20 jun 2018.

Rezende, D. A. (2007). Sistemas de informações organizacionais. São Paulo: Atlas.

Silva, F. C. L. (2018). Contextualized reflections on information and communication technology and on the empowerment of women. Dito Efeito - Revista de Comunicação da UTFPR, 9(14).

Silva, R. C. D. (2007). Gestão estratégica da tecnologia: instrumentos teóricos e aplicações. Jacobina: Rabisco.

Tanenbaum, A. S., \& Zucchi, W. L. (2009). Organização estruturada de computadores. Pearson Prentice Hall.

Valor (2018). Valor1000: As 50 maiores seguradoras. Disponível em: www.valor.com.br/valor1000/2016/ranking50maioresseguradoras. Acesso em: 22 dez. 2018.

Universia Knowledge Wharton (2013). Por que o mercado brasileiro de seguros não decolou. Disponível em: http://www.knowledgeatwharton.com.br/article/por-que-o-mercado-brasileiro-de-seguros-naodecolou/. Acesso em: 17 dez. 2018.

\title{
e-Insurance or Digital Insurance: The Information and Communication Technologies used by the main insurance companies in Brazil
}

\begin{abstract}
The share of the insurance sector in Brazil is expected to reach 7.5\% of GDP and, on the other hand, is still not very accessible to the retail population, mainly due to its costs. At the same time, information and communication technologies have been widely used to innovate businesses, organizations and companies, in order to expand services, reduce costs, increase performance and reach, as well as disseminate information. In this scenario, this research seeks to recover this discussion, presenting benefits and barriers to adoption of online services. The aim of this research is to investigate the main information and communication technologies used in online services by the largest insurers in Brazil. The discussion about e-Business and eInsurance themes in order to improve services and lower costs, allowing diffusion and expansion of people's access to services is the major contribution.
\end{abstract}

Keywords: e-Business, e-Insurance, Insurance Companies, ICT. 


\section{e-Insurance o Seguros Digitales: Las Tecnologías de Información y Comunicación utilizadas por las principales empresas aseguradoras de Brasil}

\section{Resumen}

Las aseguradoras, que componen el sector de servicios, son vistas como grandes agentes económicos. La participación del sector de seguros, de Brasil debe llegar al 7,5\% del PIB y, por otro lado, todavía es poco accesible a la población en el comercio minorista, principalmente en función de sus costos. Paralelamente, las tecnologías de información y comunicación han sido ampliamente utilizadas para innovar los negocios, las organizaciones y las sociedades, en el sentido de ampliar servicios, reducir costos, aumentar el rendimiento y el alcance, así como difundir información. En este escenario, esta investigación busca recuperar esa discusión, presentando beneficios y barreras para la adopción de servicios en línea. Para contextualizar la discusión, fueron exploradas las plataformas digitales de las cinco mayores aseguradas de Brasil, con objetivo de investigar cómo los servicios online son ofrecidos por medio de las TIC. Como contribución está la discusión de temas de e-Business y e-Insurance para perfeccionar servicios y abaratar costos, permitiendo difusión y ampliación del acceso de personas a los servicios securitarios.

Palabras Clave: e-Insurance, e-Business, TIC, Aseguradoras, Seguro.

\section{Sobre os Autores}

\section{Lucas Queiroz FERREIRA}

Graduado em Administração pela Universidade Federal de Pernambuco (UFPE)

Rodovia BR-104, Km 59, s/n - Nova Caruaru - Caruaru - PE - Brasil - CEP 55002-970.

E-mail: queirozlucas@live.com

\section{Francisco Carlos Lopes da SILVA}

Professor Adjunto da Universidade Federal de Pernambuco (UFPE), Centro Acadêmico do Agreste (CAA). Doutor em Engenharia de Produção pela Universidade de Santa Catarina (UFSC).

Rodovia BR-104, Km 59, s/n - Nova Caruaru - Caruaru - PE - Brasil - CEP 55002-970.

E-mail: francisco.clsilva@ufpe.br

\section{Érica Souza SIQUEIRA}

Doutoranda em Administração pela Escola de Administração de São Paulo (EAESP/FGV), Programa de Pós-Graduação em Administração de Empresas (EAESP/FGV)

Av. 9 de julho, 2029 - Bela Vista - São Paulo - SP - Brasil - CEP 01313-902

E-mail: erica.siqueira@fgv.edu.br 